\title{
Exogenous Hydrogen Sulfide Attenuates Cardiac Fibrosis Through Reactive Oxygen Species Signal Pathways in Experimental Diabetes Mellitus Models
}

\author{
Dan Zheng ${ }^{\mathrm{a}}$ Shiyun Dong ${ }^{\mathrm{a}}$ Ting $\mathrm{Li}^{\mathrm{a}}$ Fan Yang ${ }^{\mathrm{a}}$ Xiangjing Yu ${ }^{\mathrm{b}}$ Jichao Wu $\mathrm{W}^{\mathrm{a}}$ \\ Xin Zhong ${ }^{a}$ Yajun Zhao ${ }^{a}$ Lina Wang ${ }^{a}$ Changqing $X^{a, c}$ Fanghao Lu $^{a}$ \\ Weihua Zhanga,c
}

${ }^{a}$ Department of Pathophysiology, Harbin Medical University, ${ }^{b}$ Clinical Laboratory, Harbin Cancer Hospital of Harbin Medical University, 'Bio-Pharmaceutical Key Laboratory of Heilongjiang Province, Harbin, China

\section{Key Words}

Hydrogen sulfide - Diabetic cardiomyopathy $\cdot$ Cardiac fibrosis $-N A D P H$ oxidase $4 \cdot$ Reactive oxygen species

\begin{abstract}
Background: Oxidative stress inducing hyperglycemia and high glucose play an important role in the development of cardiac fibrosis associated with diabetic cardiomyopathy. The endogenous gasotransmitter hydrogen sulfide $\left(\mathrm{H}_{2} \mathrm{~S}\right)$ can act in a cytoprotective manner. However, whether $\mathrm{H}_{2} \mathrm{~S}$ could inhibit the fibrotic process is unclear. The purpose of our study was to examine the role of $\mathrm{H}_{2} \mathrm{~S}$ in the development and underlying mechanisms behind diabetic cardiomyopathy. Methods: Diabetic cardiomyopathy was induced in rats by injection of streptozotocin (STZ). Cardiac fibrosis and proliferation of rat neonatal cardiac fibroblasts were induced by hyperglycemia and high glucose. We tested the effects of GYY4137 (a slowreleasing $\mathrm{H}_{2} \mathrm{~S}$ donor), $\mathrm{NaHS}$ (an exogenous $\mathrm{H}_{2} \mathrm{~S}$ donor) and NADPH oxidase 4 (NOX4) siRNA on reactive oxygen species (ROS) production, MMP-2,9, cystathionine- $\gamma$-lyase (CSE), NOX4, and extracellular signal-regulated kinase $1 / 2(E R K 1 / 2)$ to reveal the effects of $\mathrm{H}_{2} \mathrm{~S}$ on the cardiac fibrosis of diabetic cardiomyopathy. Result: In vivo, NaHS treatment inhibited hyperglycemiainduced expression of type I and III collagen, MMP-2 and MMP-9 in diabetic hearts. Rat neonatal cardiac fibroblast migration and cell survival were inhibited by administration of GYY4137. NOX4 expression was increased by hyperglycemia and high glucose, but was reduced in cardiac fibroblasts treated by NaHS and GYY4137. ROS production, ERK1/2 phosphorylation and MMP-2 and 9 expression were decreased in rat neonatal cardiac fibroblasts treated with GYY4137 and NOX4 siRNA. Conclusion: The present study shows that enhanced NOX4 expression results in cardiac fibrosis through ROS-ERK1/2-MAPkinasedependent mechanisms in diabetic cardiomyopathy. NOX4 could be an important target for $\mathrm{H}_{2} \mathrm{~S}$ to regulate redox homeostasis in cardiac fibrosis of diabetic cardiomyopathy.

Copyright (C) 2015 S. Karger AG, Basel

D. Zheng and S. Dong represents equal contribution to this paper
\end{abstract}

Weihua Zhang,

Fanghao Lu

\section{KARGER 125}

Department of Pathophysiology, Harbin Medical University

No. 157 Baojian Road, Nan Gang District, Harbin, Heilongjiang Province. 150086 (P.R.China); E-Mail zhangwh116@126.com and E-Mail lufanghao1973@126.com 


\section{Cellular Physiology Cell Physiol Biochem 2015;36:917-929 \\ \begin{tabular}{l|l} 
DOI: 10.1159/000430266 & $\begin{array}{l}\text { O 2 2015 S. Karger AG, Basel } \\
\text { www.karger.com/cpb }\end{array}$ \\
\hline
\end{tabular} \\ Zheng et al.: $\mathrm{H}_{2} \mathrm{~S}$ Reduces Cardiac Fibroblast Proliferation in Type I Diabetes Mellitus}

\section{Introduction}

Diabetic cardiomyopathy (DCM) is defined as the ventricular dysfunction occurring in diabetic patients independent of other causes, such as coronary artery disease, hypertension or dilated cardiomyopathy [1-3]. Cardiac fibrosis is a major feature of DCM, which leads to over-production of extracellular matrix (ECM) protein and results in cardiac dysfunction [4]. Recently, studies have shown that the harmful effects of oxidative stress on the diabetic heart include abnormal gene expression and activation of a number of secondary messenger pathways that can further induce cardiomyocyte death and cardiac fibrosis [5]. Reactive oxygen species (ROS)play a central role in the pathogenesis of diabetic cardiomyopathy $[6,7]$. Recent studies have demonstrated that NOX-dependent ROS production is involved in initiation of cardiac fibrosis. NOXs are major enzymes responsible for the production of superoxide $\left(\mathrm{O}^{2-}\right)$ by transferring electrons across the membrane from NADPH to molecular oxygen. The NOX4 isoform is expressed in the cytoplasm and mitochondria of the heart, and up-regulation of NOX4 may have a direct influence on increasing oxidative stress [8-10].

Hydrogen Sulfide $\left(\mathrm{H}_{2} \mathrm{~S}\right)$ is a physiological gas transmitter with diverse physiological functions including anti-inflammation, vessel relaxation, and cardioprotection [11-14]. Endogenous $\mathrm{H}_{2} \mathrm{~S}$ is produced from cysteine by cystathionine- $\gamma$-lyase (CSE), cystathionine$\beta$-synthetetase (CBS), and 3-mercaptopyrurate sulfurtranferase (3-MT). CSE is expressed predominantly in the heart and smooth muscle cells in the cardiovascular system $[15,16]$. Recently, some research groups revealed that treatment with $\mathrm{H}_{2} \mathrm{~S}$ ameliorated the process of cardiac remodeling in an injured and failing heart and contributed to cardioprotection [17]. Some datas showed that promoting the activity of CSE could modulate antioxidant defenses and protect against myocardial apoptosis [18]. Sheng et al. supported data that $\mathrm{H}_{2} \mathrm{~S}$ might potentially modulate cardiac fibrosis by inhibiting functioning of potassium channels., leading to decreased proliferation and suppression of transforming growth factor-b1 (TGF-b1)-induced myofibroblast transformation of atrial fibroblasts [19]. However, the mechanism behind $\mathrm{H}_{2} \mathrm{~S}$ protection against myocardial remodeling is unclear.

This present study provides the first evidence that exogenous or endogenous $\mathrm{H}_{2} \mathrm{~S}$ inhibits diabetic fibrotic responses. Our data also revealed that $\mathrm{H}_{2} \mathrm{~S}$ suppressed diabetic cardiac fibrosis through regulation of the NOX4-ROS-ERK signaling pathway.

\section{Materials and Methods}

\section{Animal care}

Male Wistar rats weighing 200-250 g were obtained from the Experimental Animal Center of Harbin Medical University (Harbin, People's Republic of China).The animals were housed in the animal care facility at the Harbin Medical University. All animal care and experimental protocols complied with the Animal Management Rules of the Ministry of Science and Technology of the People's Republic of China. The Animal Research Ethics Committee at Harbin Medical University approved all animal and animal protocols.

Diabetes model and experimental groups

Diabetes was induced by tail vein injection of STZ (streptozotocin, $50 \mathrm{mg} / \mathrm{kg}$ ) dissolved in $0.1 \mathrm{M}$ citrate buffer ( $\mathrm{pH} 4.5$ ), the control group was injected with citrate buffer alone [20]. Glucose (10\%) was added into the drinking water of STZ-treated rats during the first $24 \mathrm{~h}$ to reduce the hypoglycemic phase that follows STZ injection. Blood glucose levels of the rats were measured using blood glucose test strips $72 \mathrm{~h}$ after STZ injection, and blood glucose levels over $16.7 \mathrm{mmol} / \mathrm{L}$ were considered to be diabetic. Rats were divided into 4, 8 and 12 week Dia (diabetic) groups and Dia+NaHS treatment groups. The NaHS treatment groups received daily intraperitoneal injections of NaHS $(100 \mu \mathrm{M})$. Measurement of blood glucose was repeated after 2 weeks of treatment in each group.

\section{Hemodynamic measurement}

Cardiac functions were assessed using an echocardiography system (GEVIVID7 10S, USA). Echocardiograms were performed on self-breathing rats under anesthesia (intraperitoneal injection of $10 \%$ 


\section{Cellular Physiology Cell Physiol Biochem 2015;36:917-929

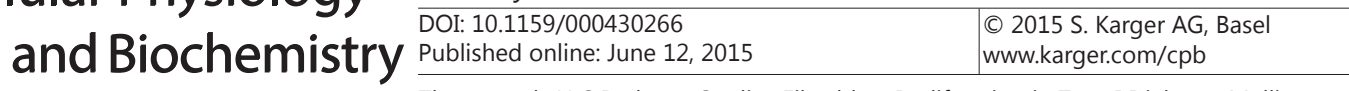 \\ Zheng et al.: $\mathrm{H}_{2} \mathrm{~S}$ Reduces Cardiac Fibroblast Proliferation in Type I Diabetes Mellitus}

chloral hydrate at $0.3 \mathrm{~mL} / 100 \mathrm{~g}$ body weight) [21]. Left ventricular (LV) systolic and diastolic parameter measurements included left ventricular fractional shortening (LVFS), left ventricular ejection fraction (LVEF), left ventricular end diastolic volume (LVEDV) and left ventricular posterior wall diameter (LVPWd). All parameters represent the means of five consecutive cardiac cycles.

Neonatal rat cardiac fibroblasts culture and treatment

Primary cultures of neonatal rat fibroblasts were prepared by previously described methods [22]. Briefly, the rats hearts were isolated by mincing the appendages to less than $1 \mathrm{~mm}^{3}$ and incubated with 0.25 $\%$ trypsin for $10 \mathrm{~min}$ at $37^{\circ} \mathrm{C}$. The supernatant cells were collected. Cells were cultured as monolayers at a density of $5 \times 10^{4} \mathrm{cells} / \mathrm{cm}^{2}$ at $37^{\circ} \mathrm{C}$ in a humidified atmosphere containing $5 \% \mathrm{CO}_{2}$. After a $1 \mathrm{~h}$ incubation at $37{ }^{\circ} \mathrm{C}$, in a humidified atmosphere with $5 \% \mathrm{CO}_{2}$, the unattached cells were discarded and the attached cells were continuously cultured. The media was changed two times per week.

The cultured cardiac fibroblasts were randomly divided into five groups: control (low glucose, LG, 5.5 mmol/L), high glucose (HG, $25.0 \mathrm{mmol} / \mathrm{L}), \mathrm{HG}+\mathrm{NaHS}(100 \mu \mathrm{M}), \mathrm{HG}+\mathrm{GYY} 4137$ (100 nmol), HG+PD98059 $(10 \mathrm{nmol})$ and $\mathrm{HG}+\mathrm{NAC}(10 \mathrm{mmol})$. Drugs were dissolved in pre-warmed media and added directly to the culture for $24 \mathrm{~h}$.

\section{Cell proliferation assay}

Cell proliferation assay was performed with BrdU kit (Roche, Basel,Switzerland). Briefly, single rat cardiac fibroblast were loaded with BrdU labelling solution $(100 \mu \mathrm{M})$ diluted 10 times in DMEM $(0.1 \% \mathrm{FBS})$ was added to each well and the plates were incubated at $37^{\circ} \mathrm{C}$ for an additional $2 \mathrm{hrs}$. Incorporated $\mathrm{BrdU}$ was detected by an anti-BrdU antibody for $90 \mathrm{~min}$. and colorimetric development proceeded for $15 \mathrm{~min}$. Fluorescence in cells was visualized using a Zeiss Axioplan microscope.

Scratch wound repair assay

Cardiac fibroblasts were treated with high glucose, $\mathrm{HG}+\mathrm{GYY} 4137$, and $\mathrm{HG}+\mathrm{A} 23187$ and then subjected to the in vitro scratch assay as described previously. Images were captured at 0 and 24 hours after treatment using phase-contrast microscopy.

\section{Mitochondrial ROS production}

Mitochondrial ROS production was measured using MitoSOX Red mitochondrial superoxide indictor (Invitrogen). Single rat cardiac fibroblast were loaded with $5 \mu \mathrm{mol} / \mathrm{L}$ MitoSOX Red at room temperature for $15 \mathrm{~min}$. MitoSOX Red fluorescence was measured at $583 \mathrm{~nm}$ following excitation at $488 \mathrm{~nm}$ using a Zeiss LSM 510 inverted confocal microscope.

\section{The level of cellular ROS production}

Intracellular ROS levels were examined using the DCFH-DA staining method based on the conversion of non-fluorescent DCFH-DA to the highly fluorescent DCF upon intracellular oxidation by ROS. The neonatal rat cardiac fibroblasts were seeded on coverslips and incubated $\left(1 \mathrm{~h}, 37^{\circ} \mathrm{C}\right.$, in the dark in serumfree media containing DCFH-DA $(10 \mu \mathrm{M} / \mathrm{L})$ in the presence of high glucose, GYY4137, A23187 and NAC with high glucose. After washing twice with PBS, coverslips were placed on glass slides and the amount of DCF fluorescence in cells was visualized using a Zeiss Axioplan microscope. In the experiments, the mean fluorescence intensity from 10,000 events was analyzed using Summit v4.3 software (Beckman-Counlter, CA, USA ).

Total protein extraction from rat cardiac tissues and neonatal rat cardiac fibroblasts and western blot analysis

Rat cardiac tissues and neonatal rat cardiomyocytes were homogenized in $0.5 \mathrm{~mL}$ of RIPA buffer prior to being transferred into small tubes and rotated for $1 \mathrm{~h}$ at $4^{\circ} \mathrm{C}$. Solubilized proteins were collected after centrifugation at $3000 \mathrm{rpm}$ for $30 \mathrm{~min}$. The supernatant was collected and stored at $-80^{\circ} \mathrm{C}$. To detect CSE, MMP-2 and 9, collagen-I and III, and NOX4 protein levels, protein lysates from each group of cells or tissues were separated by SDS-PAGE and transferred onto a PVDF membrane (Millipore) via electrophoresis. Polyacrylamide gels (12\%) were used for CSE (42 kDa), NOX4 (62 kDa), MMP-2 and 9 (72 kDa and 67$92 \mathrm{kDa}$ ), collagen-I and III (129 kDa and $140 \mathrm{kDa}$ ), and p-ERK/ERK (42-44 kDa). The membranes were 


\section{Cellular Physiology Cell Physiol Biochem 2015;36:917-929

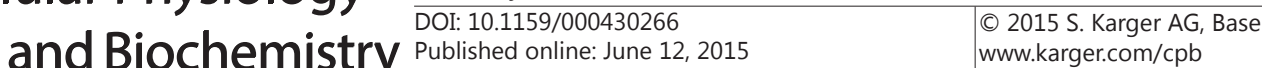 \\ Zheng et al.: $\mathrm{H}_{2} \mathrm{~S}$ Reduces Cardiac Fibroblast Proliferation in Type I Diabetes Mellitus}

blocked with $5 \%$ nonfat milk in TBS $+0.2 \%$ Tween 20 for $2 \mathrm{~h}$ at room temperature. Immunoblotting was then performed using $2 \mu \mathrm{g} / \mathrm{mL}$ rabbit anti-rat CSE and MMP-2 and 9 antibodies, and rabbit anti-human collagen-I and III polyclonal antibody. Membranes were then washed and incubated with anti-rabbit IgG antibodies at a 1:5000 dilution. Immunoreactive proteins were then visualized using the ECL plus western blot detection system. Protein bands were quantified using a Bio-Rad Chemi EQ densitometer and Bio-Rad Quantity One software (Bio-Rad laboratories, Hercules, USA).

NOX4 short interfering RNA transfection.

The rat neonatal cardiac fibroblasts ( $80 \%$ confluent) were treated according to the manufacturer's instructions with NOX4 short interfering RNAs (siRNAs) (mouse; Santa Cruz Biotechnology) for $48 \mathrm{~h}$ to inhibit NOX4 expression. Knockdown of NOX4 was confirmed by western blot analysis of NOX4 protein expression.

Statistical analysis

Data are expressed as mean \pm SEM. All data involving multiple groups were analyzed using a one-way ANOVA. Differences between individual groups were analyzed using the student's t-test. A difference of $\mathrm{p}<0.05$ was considered statistically significant.

\section{Result}

General parameters in STZ-induced diabetic rats

We examined blood glucose levels and the volume of water and food intake in STZinduced diabetic rats. Blood glucose levels were elevated in 4-week-old $(29.5 \pm 5.4 \mathrm{mmol} / \mathrm{L}$, $\mathrm{p}<0.01)$ and 8 -week-old $(25.6 \pm 4.2 \mathrm{mmol} / \mathrm{L}, \mathrm{p}<0.01)$ rats compared to the control group $(5.2 \pm 0.5 \mathrm{mmol} / \mathrm{L})$. The volume of water and food intake was elevated in 4-week-old $(183 \pm 4.9$ $\mathrm{mL} / \mathrm{d}$ and $39.4 \pm 2.3 \mathrm{~g} / \mathrm{d}$, respectively) and 8 -week-old $(228 \pm 5.6 \mathrm{~mL} / \mathrm{d}$ and $46.8 \pm 2.5 \mathrm{~g} / \mathrm{d}$, respectively, $\mathrm{p}<0.01$ ) rats compared to the control $(27 \pm 3.1$ and $13.2 \pm 1.5$, respectively) group.

Cardiac fibrosis and cardiac functions detected by Masson's Trichrome Stain and echocardiography

Masson Trichrome Stain was used to identify areas of collagen deposition by the blue color. Collagen accumulation was significantly increased in the Dia-4w (diabetes- $4 \mathrm{w}$ ) and Dia-8w (diabetes-8w) groups compared to the control and NaHS treatment groups (Fig. 1a).

Additionally, the cardiac structure and function of rats with STZ-induced diabetes was examined by echocardiography. The LVEF was decreased in the Dia-4w, Dia-8w and Dia-8w+NaHS groups compared with the control group, but returned to normal after administration of NaHS for 4 weeks. The LVFS was decreased in the Dia-8w group compared with the control group, but other groups had no obvious changes.The LVPWd and LVEDV in the diabic and NaHS for $4 \mathrm{w}$ and $8 \mathrm{w}$ groups had no obvious changes compared with the NaHS treatment groups (Fig. 1b).

Exogenous $\mathrm{H}_{2} \mathrm{~S}$ inhibits hyperglycemia-induced MMP and collagens expression in rat hearts

Our previous study demonstrated that endogenous $\mathrm{H}_{2} \mathrm{~S}$ production was reduced in DCM. To determine CSE expression in DCM, the protein levels of CSE in rat cardiac tissue was determined by western blotting (Fig. 2a). The CSE protein content in the Dia-8w group was lower than that in the control group. This result shows that hyperglycemia could downregulate the expression of CSE in cardiac tissues.

Sustained induction and activation of matrix metalloproteinases (MMPs) and the destruction and deposition of the extracellular matrix (ECM) are hallmarks of cardiac fibrosis. MMPs are involved in the remodeling process of cardiac fibrosis [23]. To further investigate if exogenous $\mathrm{H}_{2} \mathrm{~S}$ could ameliorate hyperglycemia-induced cardiac fibrosis, expression of MMPs and collagen was examined by western blotting. As shown in Fig. 2b 


\section{Cellular Physiology Cell Physiol Biochem 2015;36:917-929 \begin{tabular}{l|l|l} 
DOI: 10.1159/000430266 & (c) $2015 \mathrm{~S}$. Karger AG, Base
\end{tabular}

Fig. 1. Effects of treatment with LPS or LPS plus equol on live cells after 24 h. The data are shown as percentages of the control, untreated macrophages. Means not sharing the same letter differ $(\mathrm{P}$ $<0.05$ ) by the LSD test; the vertical bar is the SE derived from the ANOVA error mean square for $\mathrm{n}=$ 6 replicated wells. a
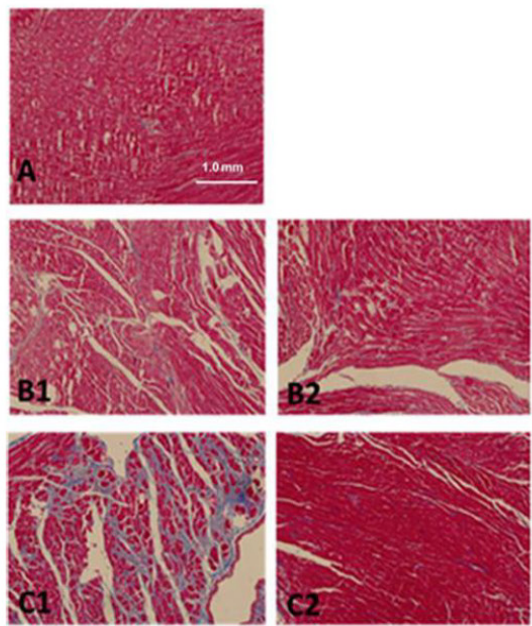

$\mathrm{b}$

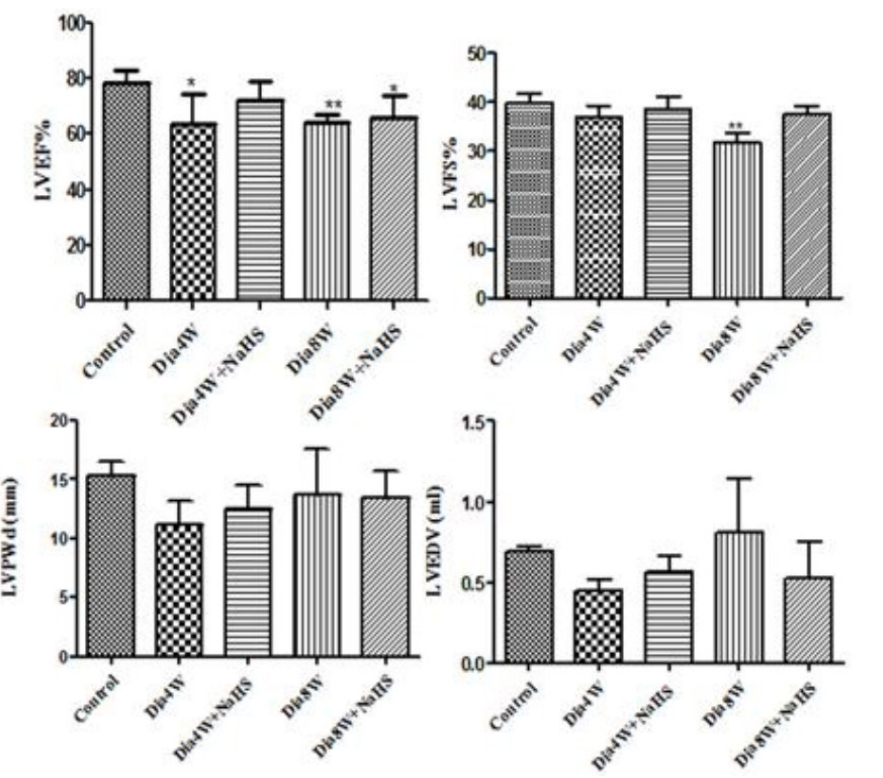

and Fig. 2c, protein levels of MMP-2 and MMP-9 were significantly higher in the Dia-4w and Dia-8w groups when compared to the control group. However, the protein levels of MMP-2 and -9 in the STZ-induced diabetic rats treated with NaHS was reduced when compared with the Dia-4w and Dia-8w groups. These results demonstrate that exogenous $\mathrm{H}_{2} \mathrm{~S}$ can inhibit cardiac fibrosis in DCM through the regulation of MMP-2 and MMP-9 expression.

Preliminary studies have shown that collagen-I is mainly expressed in the skin and tendons, whereas collagen-III is mostly found in cardiovascular system [24]. To further study the severity of cardiac fibrosis, the collagen-I and collagen-III protein levels were examined in the Dia-4w and Dia-8w groups. Our results show that these two collagens are significantly expressed in the Dia-4w and Dia-8w groups (Fig. 2d and Fig. 2e).

Effects of the CSE $/ \mathrm{H}_{2} S$ system on cell proliferation and migration in neonatal cardiac fibroblasts

To further examine if endogenous $\mathrm{H}_{2} \mathrm{~S}$ can modulate proliferation, neonatal cardiac fibroblast were cultured. Vitmetin is a specific protein marker for fibroblasts. In neonatal 
Cellular Physiology Cell Physiol Biochem 2015;36:917-929

\begin{tabular}{l|l} 
Dor: 10.1159/000430266 & 2015 S. Karger AG, Basel \\
and Buw.karger.com/cpb
\end{tabular}

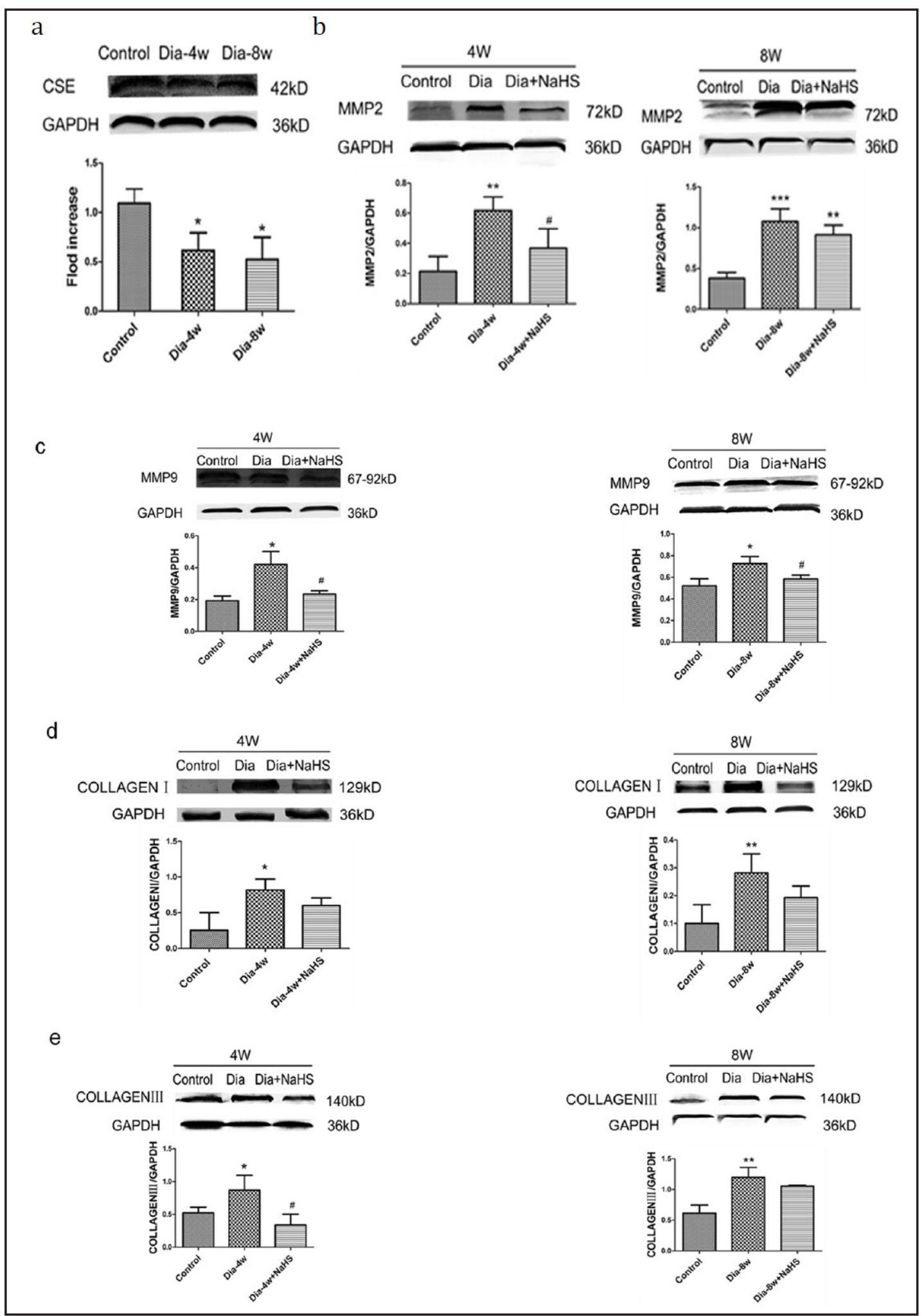

Fig. 2. (a) Western blotting analysis showing CSE expression in STZ-induced diabetic myocardial fibrosis model. The effect of NaHS on extracellular matrix and collagen production. Expression of (b) MMP-2 (c) MMP-9 (d) Collagen I (e) Collagen III in Dia-4w and Dia-8w protein levels were normalized to GAPDH ( $\mathrm{n}=4-5$ ), ${ }^{*} P<0.05$ vs. Control group, ${ }^{* *} P<0.01$ vs. Control group, ${ }^{* * *} P<0.001$ vs. Control group, $\# P<0.05$ vs. Dia group. 


\section{Cellular Physiology Cell Physiol Biochem 2015;36:917-929 and Biochemistry \begin{tabular}{l|l} 
DOI: 10.1159/000430266 & $\begin{array}{l}\text { O 2015 S. Karger AG, Basel } \\
\text { puww.karger.com/cpb }\end{array}$ \\
\cline { 2 - 3 }
\end{tabular} \\ Zheng et al.: $\mathrm{H}_{2} \mathrm{~S}$ Reduces Cardiac Fibroblast Proliferation in Type I Diabetes Mellitus}

Fig. 3. (a) Immunofluorescence staining Vitmetin protein in neonatal cardiac fibroblasts. (b) Cell proliferation reduced by activation of GYY4137, as evidenced by Brdu staining, ** $P<0.01$ vs. Control group, \# $P<0.05$ vs. High glucose group, \#\# $P<0.01$ vs. High glucose group, \# $\mathrm{p}<0.05$ vs. High glucose group. (c) Scratch wound repair assay for observation of neonatal cardiac fibroblast migration, ${ }^{*} P<0.05$ vs. Control group, ** $P<0.01$ vs. Control group, \#\# $P<0.01$ vs. HG group.

a
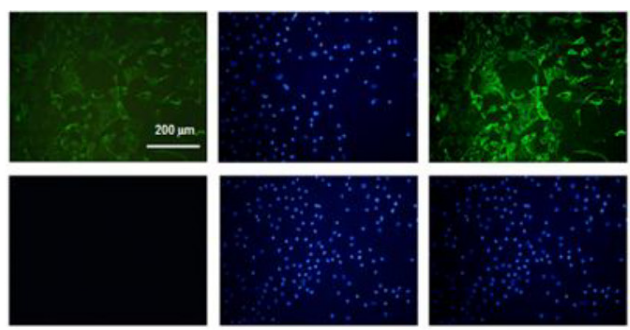

$\mathrm{b}$

Control High glucose HG+GYY4137 HG+A23187 HG+NAC
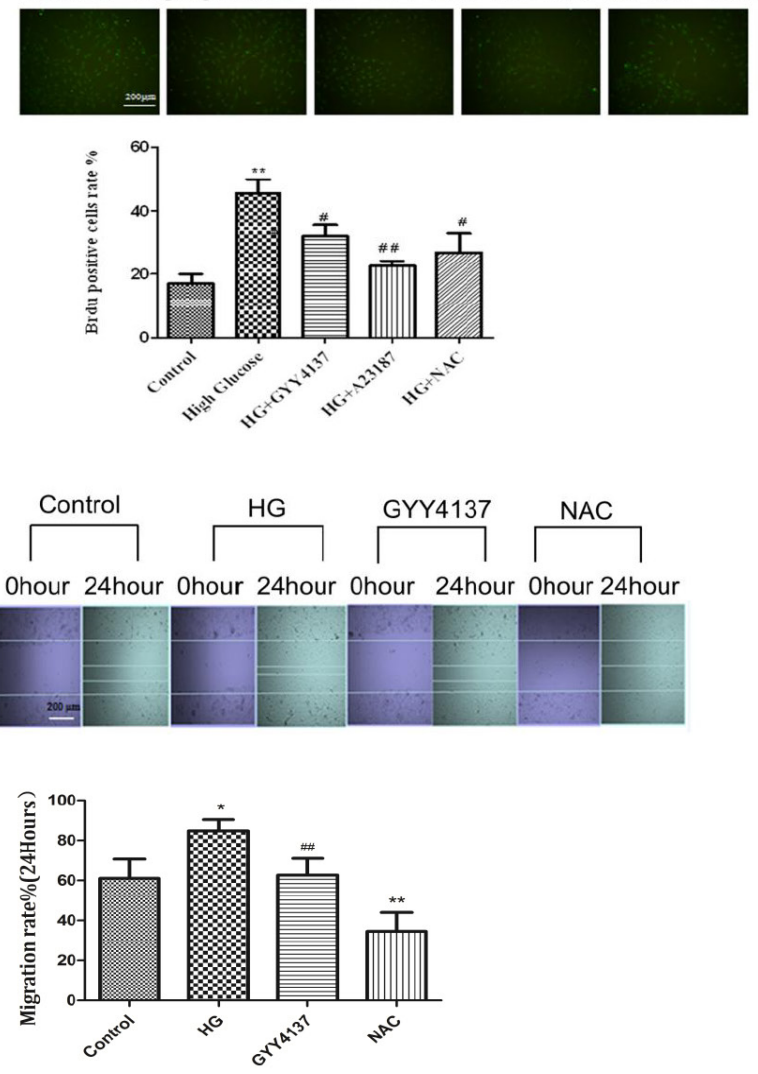

cardiac fibroblasts, deep green fluorescence is referred to as Vitmetin positive. The amount of positive cardiac fibroblasts was greater than $90 \%$ in all cultured cells (Fig. 3a).

Cell proliferation assay was performed with BrdU assay to study whether neonatal cardiac fibroblast proliferation is regulated by $\mathrm{CSE} / \mathrm{H}_{2} \mathrm{~S}$. The neonatal cardiac fibroblasts were starved overnight and pretreated with GYY4137 (a slow releasing $\mathrm{H}_{2} \mathrm{~S}$ donor), NAC (a ROS scavenger), or A23187 for 48 hours. As shown in Fig. 3b, GYY4137 and NAC inhibited cardiac fibroblast proliferation.

To investigate whether the migration of neonatal cardiac fibroblasts is induced by CSE/ $\mathrm{H}_{2} \mathrm{~S}$, cell migration was studied in a wound-healing assay. Neonatal cardiac fibroblasts were scraped off with a pipette tip to produce a wide acellular area. The results show that the acellular areas were significantly decreased after $12 \mathrm{~h}$ and $24 \mathrm{~h}$ incubations when cells were treated with 100 nmol GYY4137 and NAC (Fig. 3c).

\section{The level of ROS in mitochondrial and cytoplasm fractions}

Our previous mitochondria study showed that exogenous $\mathrm{H}_{2} \mathrm{~S}$ inhibits apoptosis in cardiac myocytes in diabetic rats and that the mechanism is associated with the reduction of mitochondrial ROS production [20]. The level of mitochondrial ROS was measured using 


\section{Cellular Physiology Cell Physiol Biochem 2015;36:917-929 \begin{tabular}{l|l} 
DOI: 10.1159/000430266 & \\
and Biochemistry Published online: June 12, 2015 & $\begin{array}{l}\text { O 2015 S. Karger AG, Basel } \\
\text { www.karger.com/cpb }\end{array}$ \\
\cline { 2 - 3 }
\end{tabular}

Fig. 4. (a) The level of ROS measured by the relative MitoSOX Red fluorescence. Effect of NaHS on the level of ROS in neonatal rat cardiomyocytes. Data for the relative changes of MitoSOX Red fluorescence. Data are the mean \pm SEM. $\quad * * P<0.01$ vs. Control group, $\# P<0.05$ vs. High glucose group. (b) Intracellular ROS levels were examined using DCFH-DA staining method, based on the conversion of nonfluorescent DCFH-DA to the highly fluorescent DCF upon intracellular oxidation by ROS. High glucose stimulates ROS generation in neonatal cardiac fibroblasts, with GYY4137 reversing the response observed. *** $P<0.001$ vs. Control group, \#\#\# $P<0.001$ vs. High glucose group. (c) Western blotting analysis the
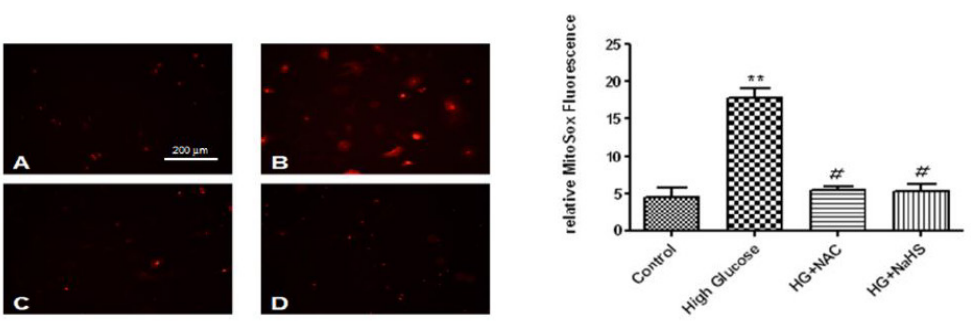

b

Control High glucose HG+GYY4137 HG+A23187 HG+NAC
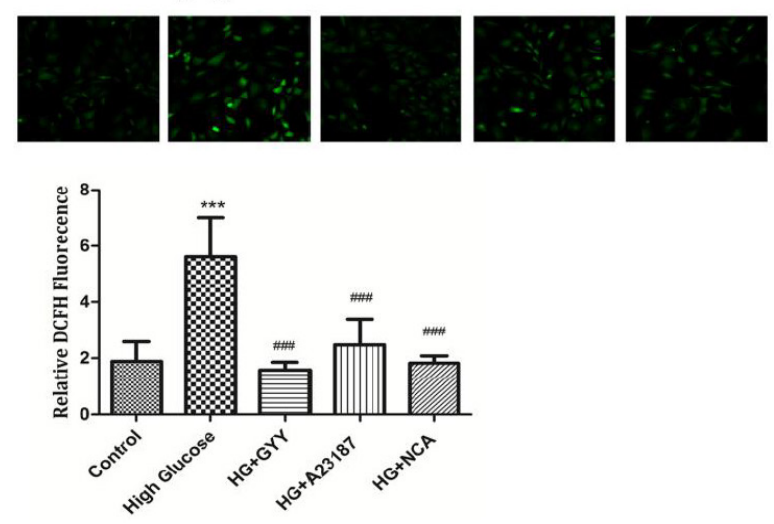

Control HG GYY4137 A23187 NAC

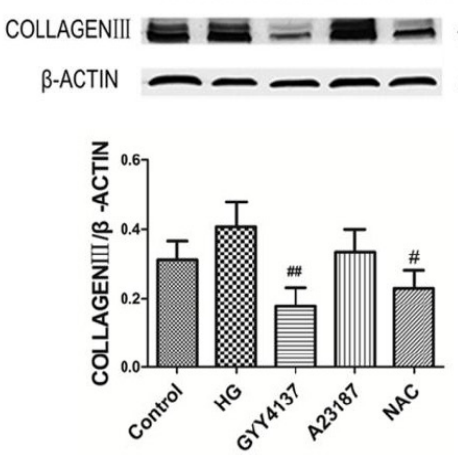

Control HG GYY4137 A23187 NAC
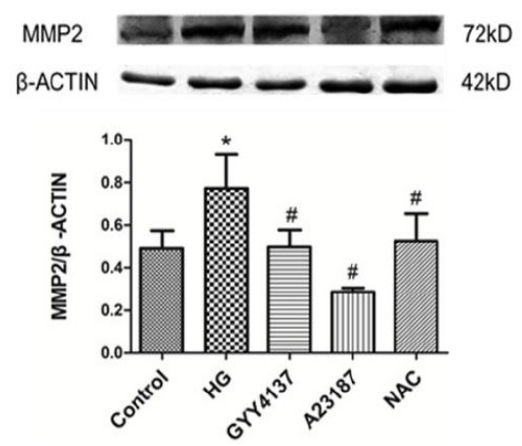

effect of NaHS on extracellular matrix and collagen production. Expression of Collagen III and MMP-2 in neonatal cardiac fibroblasts protein levels were normalized to $\beta$-actin ( $n=4-5),{ }^{*} P<0.05$ vs. Control group, \# $P<0.05$ vs. High glucose group, \#\# $P<0.01$ vs. High glucose group.

MitoSox Red in neonatal rat cardiomyocytes (Fig. 4a). ROS production significantly increased in the HG (high glucose) group compared to the control group. However, ROS production in the NAC and NaHS treatment groups was notably decreased compared to the HG group. These results show that exogenous $\mathrm{H}_{2} \mathrm{~S}$ reduces ROS production in neonatal cardiac fibroblasts.

In order to explore whether GYY4137 has a pro-oxidant effect on our experimental model, levels of intracellular ROS were assessed using DCFH-DA, a specific oxidation-sensitive fluorescent probe. The fluorescence intensity (oxidized DCF), indicative of ROS levels, was remarkably increased in high-treated cells compared to the control group. Preincubation of cells with GYY4137 (100 nmol) inhibited up-regulation of ROS by high glucose in a dosedependent manner. Similarly, NAC decreased the level of ROS induced by high glucose (Fig. $4 \mathrm{~b})$.

\section{KARGER}




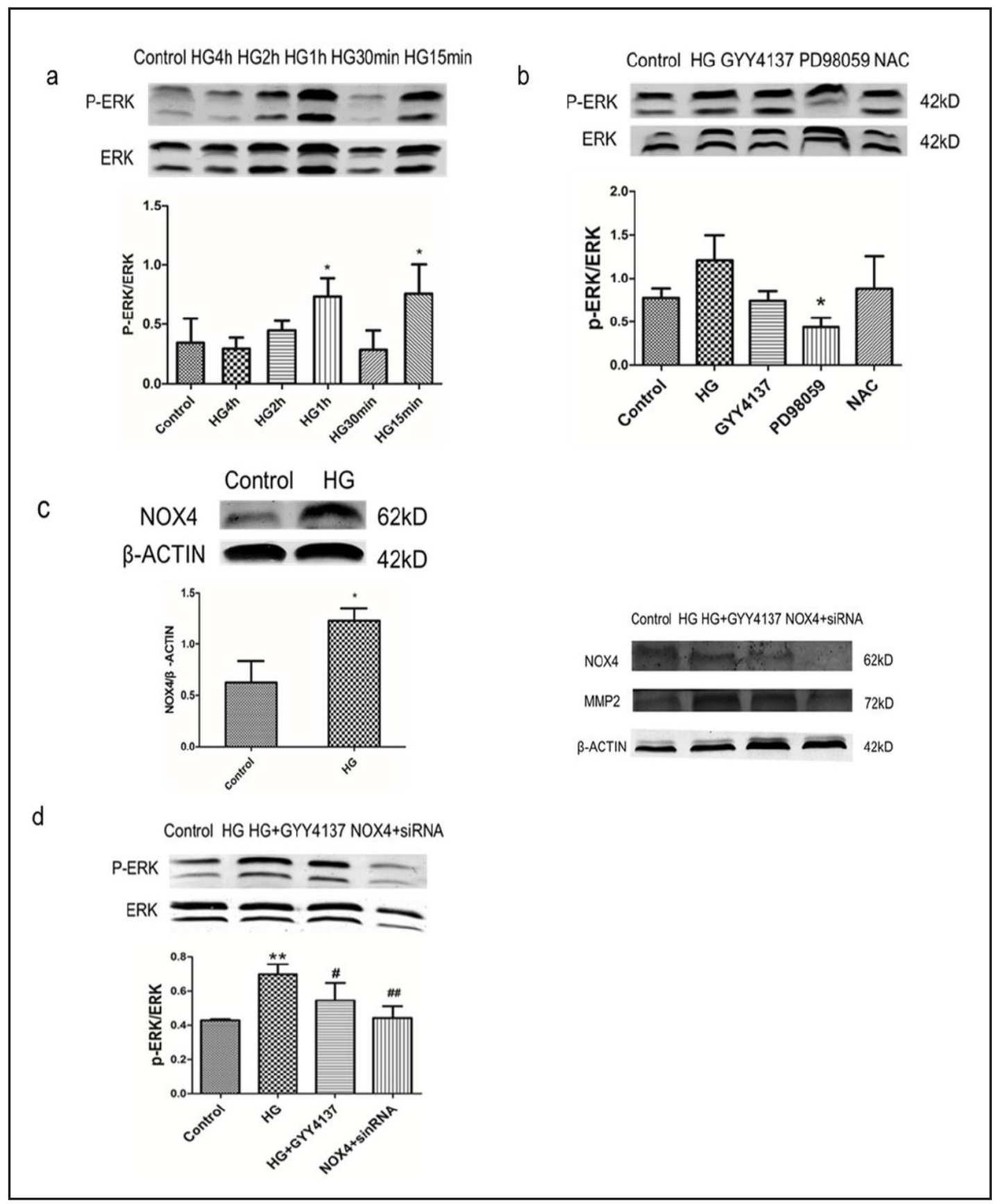

Fig. 5. Western blotting. examined (a) the expression of the p-ERK1/2/ERK1/2 at different time points in cardiac fibroblasts , (b) the phosphorylation of ERK1/2 content in neonatal rat fibroblasts in high glucose. (c) Western blotting analysis the expression of NOX4 and MMP-2, (d) the phosphorylation of ERK1/2 content by transfected with NOX4siRNA.The intensity of each band was quantified by densitometry, and the data were normalized to the $\beta$-actin. The fold change values represent the mean \pm SEM of three determinations. ${ }^{*} P<0.05$ vs. Control group, ${ }^{* *} P<0.01$ vs. Control group, $\# P<0.05$ vs. High glucose group, $\# \# P<0.01$ vs. High glucose group.

Effects of CSE $/ \mathrm{H}_{2}$ Son extracellular matrix (ECM) production in neonatal cardiac fibroblasts MMPs not only play an important role in matrix degradation, but are also involved in collagen synthesis regulation. To determine the effect of $\mathrm{CSE} / \mathrm{H}_{2} \mathrm{~S}$ on the regulation of ECM production, MMP-2 and collagen III levels were examined by western blotting. As shown in KARGER 


\section{Cellular Physiology Cell Physiol Biochem 2015;36:917-929 \\ \begin{tabular}{c|c|c} 
DOI: 10.1159/000430266 & $\begin{array}{l}\text { O 2015 S. Karger AG, Base } \\
\text { www.karger.com/cpb }\end{array}$
\end{tabular} \\ Zheng et al.: $\mathrm{H}_{2} \mathrm{~S}$ Reduces Cardiac Fibroblast Proliferation in Type I Diabetes Mellitus}

Fig. 4c, the expression of collagen III and MMP-2 was significantly reduced by treatment with GYY4137 and A23187 when compared to the control group. Our results show that GYY4137 can attenuated cardiac fibroblast proliferation in the HG group. The effect of $\mathrm{CSE} / \mathrm{H}_{2} \mathrm{~S}$ activation could ameliorate the myocardial dysfunction in STZ-induced diabetic myocardial fibrosis.

Exogenous H2S regulates cardiac fibroblasts proliferation by activation of NOX4-ROSERK1/2 signaling

Some studies have shown that NOX-mediated ROS induces ROS activation through the oxidation of specific thiols and thereby leads to activation of the ERK1/2 pathway [25]. To assess the signaling pathways potentially involved in the cardiac remodeling process induced by diabetes, we examined the expression of p-ERK1/2/ERK1/2 at different time points in cardiac fibroblasts. As shown in Fig. $5 a$ and b, there was a marked increase in p-ERK1/2 expression at 1 hour, whereas PD98059, a specific ERK1/2, inhibitor, reduced p-ERK1/2 in the cardiac fibroblasts treated with high glucose. Consistent with this, GYY4137 significantly decreased p-ERK1/2 expression in the cardiac fibroblasts treated with high glucose.

To determine whether NOX4 mediated high glucose-induced neonatal cardiac fibroblast proliferation through the ERK pathway, cells were transfected with control or NOX4 siRNA. Transfection with NOX4 siRNA reduced NOX4 protein expression when compared to normal and high glucose controls (Fig. 5c). Densitometry analysis showed that NOX4 siRNA transfection decreased high glucose-induced NOX4 protein levels by greater than $50 \%$ compared to the high glucose group. Following transfection, NOX4 siRNA-transfected neonatal cardiac fibroblasts were placed in high glucose condition for 48 hours and then analyzed for p-ERK1/2 expression by western blotting. Transfection with NOX4 siRNA and GYY4137 significantly decreased p-ERK1/2 expression in the cardiac fibroblasts. These results indicate that NOX4 is a significant contributor to high glucose-induced increases in cardiac fibroblasts proliferation (Fig. 5d).

\section{Discussion}

Diabetic cardiomyopathy (DCM) is associated with diastolic dysfunction followed by altered contractile performance. DCM is attributed to changes in the composition of the extracellular matrix (ECM) with enhanced cardiac fibrosis [26]. In this study, our data demonstrated that exogenous $\mathrm{H}_{2} \mathrm{~S}$ can inhibit hyperglycemia induced fibrotic responses in cardiac fibroblasts. In addition, we demonstrate that exogenous $\mathrm{H}_{2} \mathrm{~S}$ is involved in antifibrotic activity in high glucose-activated cardiac fibroblasts and cardiac tissues in diabetic cardiomyopathy through the regulation of the NOX4-ROS-ERK pathway.

Oxidative stress is thought to be an initial and important step in the development of diabetic cardiomyopathy [27]. ROS production appears to be a direct consequence of hyperglycemia. Recent studies have suggested that the effect of ROS may be highly dependent upon its source, location, and local concentration [28]. There has been a significant focus on the potential role of ROS-generating nicotinamide adenine dinucleotide phosphate (NADPH) oxidase 4 (NOX4) family of enzymes in the pathogenesis of chronic heart failure (CHF) [29]. In particular, these enzymes appear to be especially important in redox signaling as NOXs are multi-subunit transmembrane enzymes that utilize NADPH as an electron donor to reduce oxygen to a superoxide anion and hydrogen peroxide $\left(\mathrm{H}_{2} \mathrm{O}_{2}\right)$. NOX2 and NOX4 are the predominant isoforms expressed in cardiomyocytes [30]. NOX4 is intracellular, although the precise location remains controversial. NOX4 has been reported to be located in the endoplasmic reticulum (ER) or mitochondria as well as in the nucleus [31, 32]. Although the role of NOX4 in cardiomyocyte function is still not clear, some studies have suggested that the expression of NOX4 is increased in response to cardiac stresses such as hypoxia or pressure overload $[33,34]$. In freshly cultured cardiac fibroblasts, NOX4 mRNA is abundantly expressed [35], but the in vivo contribution of cardiac fibroblast NOX4 to heart function is still 


\section{Cellular Physiology Cell Physiol Biochem 2015;36:917-929 \\ \begin{tabular}{ll|l} 
DOI: 10.1159/000430266 & O 2015 S. Karger AG, Basel \\
and Biochemistry & $\begin{array}{l}\text { Published online: June 12, 2015 } \\
\text { wwwarger.com/cpb }\end{array}$ \\
\cline { 2 - 3 }
\end{tabular} \\ Zheng et al.: $\mathrm{H}_{2} \mathrm{~S}$ Reduces Cardiac Fibroblast Proliferation in Type I Diabetes Mellitus}

unclear. Contributing to the development of fibrosis, ROS activates other signaling molecules such as mitogen-activated protein kinases (MAPK), leading to the transcription of genes encoding growth factors and ECM proteins [36]. Our results found that NOX4 expression is increased in the Dia-4w and Dia-8w groups and in neonatal cardiac fibroblasts treated with high glucose. We also found that high glucose induced an increase in mitochondrial and cytoplasmic ROS production in neonatal cardiac fibroblasts. Our results also revealed evidence of an increase in cardiac fibrosis and the expression of MMP-2 and 9 and collagen I and III in STZ-induced diabetes. In neonatal cardiac fibroblasts, high glucose increased the expression of MMP-2, collagen III and p-ERK1/2.

$\mathrm{H}_{2} \mathrm{~S}$ is a strong reducing agent. The antioxidant actions of $\mathrm{H}_{2} \mathrm{~S}$ are involved in scavenging of ROS and peroxy nitrite and elevating the activities and expression of antioxidant enzymes [37]. $\mathrm{H}_{2} \mathrm{~S}$ can interact with other oxidative species, which may scavenge ROS and nitrogen species and permit the reduction of disulfide bonds. For example, some studies have reported that $\mathrm{H}_{2} \mathrm{~S}$ can directly scavenge ROS and peroxy nitrite and reduce its toxicity. Some data also indicate that $\mathrm{H}_{2} \mathrm{~S}$ can upregulate superoxide dismmutase (SOD) to reduce oxidative stress and the production of ROS [38-40]. $\mathrm{H}_{2} \mathrm{~S}$ decreased the expression of the P47 NADPH oxidase subunit, which is related to oxidative stress stimulation via the NF- $\kappa B$ pathway. Some studies demonstrated that treatment with exogenous $\mathrm{H}_{2} \mathrm{~S}$ suppresses the expression of pro-fibrotic genes fibronectin and galectin-3 mRNA levels, and the expression of fibrotic marker CTGF in AngII-stimulated cardiac fibroblasts [14, 41, 42]. Our previous studies have shown that NaHS (a $\mathrm{H}_{2} \mathrm{~S}$ donor) was potent at inhibiting NOX4 expression and activity under oxidative stress conditions. To further understand the molecular mechanism behind this observation, we examined the effect of exogenous $\mathrm{H}_{2} \mathrm{~S}$ on the NOX4-ROS pathway, which played an important role in profibrotic response in cardiac fibrosis in diabetic cardiomyopathy. Our results show that exogenous $\mathrm{H}_{2} \mathrm{~S}$ significantly decreased high glucose-induced NOX4 expression. Similarly, the ROS scavenger NAC and NOX4 knock-down by siRNA also decreased high glucoseinduced collagen III, MMP-2 and 9 expression in cardiac tissue and cardiac fibroblasts. Our data also demonstrate that exogenous $\mathrm{H}_{2} \mathrm{~S}$ significantly inhibits high glucose-induced ROS generation in cardiac fibroblasts. Some groups have suggested a ROS mediated cardiac fibroblast melioration via an ERK1/2-dependent signaling pathway. Administration of the specific ERK1/2 inhibitor PD98059 and exogenous $\mathrm{H}_{2} \mathrm{~S}$ treatment decreased high glucoseinduced ERK1/2 phosphorylation.

In conclusion, our results demonstrate that administration of exogenous $\mathrm{H}_{2} \mathrm{~S}$ significantly inhibits cardiac fibroblast activation through suppression of NOX4-ROS-ERK1/2 signaling. By applying exogenous $\mathrm{H}_{2} \mathrm{~S}$, we may find a novel solution for attenuating the progression of diabetic cardiomyopathy.

\section{Disclosure Statement}

The authors declare no conflict of interest.

\section{Acknowledgments}

This study was supported by the National Natural Science Foundation of China (81370330, 81300164).

\section{Reference}

1 Li CJ, Lv L, Li H, Yu DM: Cardiac fibrosis and dysfunction in experimental diabetic cardimyopathy are ameliorated by alpha-lipoic acid. Cardiovas Diabetol 2012;11:73-82.

2 Boudina S, Abel ED: Diabetic cardiomyopathy revisited. Circulation 2007;115:3212-3223. 


\section{Cellular Physiology Cell Physiol Biochem 2015;36:917-929 \begin{tabular}{l|l|l} 
DOI: 10.1159/000430266 & (C) 2015 S. Karger AG, Basel
\end{tabular} and Biochemistry Published online: June 12, 2015

3 Falcao-Pires I, Leite-Moreira AF: Diabetic cardiomyopathy: understanding the molecular and cellular basis to progress in diagnosis and treatment. Heart Fail Rev 2012;17:325-344.

4 Asbun J, Villarreal FJ: The pathogenesis of myocardial fibrosis in the setting of diabetic cardiomyopathy. J Am Coll Cardiol 2006;47:693-700.

5 Aragno M, Mastrocola R, Medana C, Catalano MG, Vercellinatto I, Danni O, Boccuzzi G: Oxidative StressDependent Impairment of Cardiac-Specific Transcription Factors in Experimental Diabetes. Endocrinology 2006;147:5967-5974.

6 Zou P, Wu LL, Wu D, Fan D, Cui XB, Zhou Y, Wang C, Li L: High glucose increases periostin expression and the related signal pathway in adultrat cardiac fibroblasts. Acta Physiologica Sinica 2010;62:247-254.

7 Zhao W, Zhao T, Chen Y, Ahokas RA, Sun Y: Oxidative stress mediates cardiac fibrosis by enhancing transforming growth factor-beta1 in hypertensive rats. Mol Cell Biochem 2008;317:43-50.

8 Anejia A, Tang WH, Banisilal S, Garcia MJ, Farkouh ME: Diabetic cardiomyopathy: insights into pathogenesis, diagnostic challenges and thereputic option. Am J Med 2008;21:748-757.

9 Cail L, Wang Y, Zhou G, Chen T, Song Y, Li X, Kang YJ: Attenuation by metallothionein of early cardiac cell death via suppression of mitochondrial oxidative stress results in a prevention of diabetic cardiomyopathy. J Am Coll Cardiol 2006;48:1688-169.

10 Kuroda J, Ag T, Matsushima S, Zhai PY, Schneider M, Sadoshima J: NADPH oxidase (NOX4) is a major source of oxidative stress in the failing heart. Proc Acar Sci USA 2010;107:15565-15570.

11 Wen YD, Wang H, Kho SK, Rinkiko S, Sheng X, Shen HM, Zhu YZ: Hydrogen Sulfide Protects HUVECs against Hydrogen Peroxide Induced Mitochondrial Dysfunction and Oxidative Stress. Plos One 2013;8:5314753156.

12 Yang CT, Zhao Y, Xian M, Li JH, Dong Q, Bai HB, Xu JD, Zhang MF: A novel controllable hydrogen sulfidereleasing molecule protects human skin keratinocytes against methylglyoxal-induced injury and dysfunction. Cell Physiol Biochem 2014;34:1304-1317.

13 Avanzato D, Merlino A, Porrera S, Wang R, Munaron L, Mancardi D: Role of calcium channels in the protective effect of hydrogen sulfide in rat cardiomyoblasts. Cell Physiol Biochem 2014;33:1205-1214.

14 Guo R, Wu K, Chen J, Mo L, Hua X, Zheng D, Chen P, Chen G, Xu W, Feng J: Exogenous hydrogen sulfide protects against doxorubicin-induced inflammation and cytotoxicity by inhibiting p38MAPK/NFKB pathway in H9c2 cardiac cells. Cell Physiol Bioche. 2013;32:1668-1680.

15 Wang R: Physiological implications of hydrogen sulfide: a whiff exploration that blossomed. Physiol Rev 2012;92:791-896.

16 Ju YJ, Zhang WH, Pei YX Yang GD: H2S signaling in redox regulation of cellular functions .Can J Physiol Pharmacol 2013;91:1-7.

17 Pan LL, Liu XH, Shen YQ, Wang NZ, Xu J, Wu D, Xiong QH, Deng HY, Huang GY, Zhu YZ: Inhibition of NADPH oxidase 4-related signaling by sodium hydrosulfide attenuates myocardial fibrotic response. Int J Cardiol 2013;168:3770-3778.

18 Huang CR, Kan JT, Liu X, MaFF, Tran H, Zou YZ, Wang SJ, Zhu YZ: Cardioprotective Effects of a Novel Hydrogen Sulfide Agent-Controlled Realease Formulation of S-Propargyl-Cysteine on Heart Failure Rats and Molecular Mechanisms. PLoS One 2013;8:e669205.

19 Sheng JW, Shim W, Wei HM, Lim SY, Liew R, Lim TS, Ong BH, Chua YL, Wong P: Hydrogen sulphide suppresses human atrial fibroblast proliferation and transformation to myofibroblasts. J Cell Mol Med 2013;17:1345-1354.

20 Zhong X, Wang LH, Wang YW, Dong SY, Leng XN, Yang GD, Wu LY, Wang R, Lu FH, Zhang WH: Exogenous hydrogen sulfide attenuates diabetic myocardial injury through cardiac mitochondrial protection. Mol Cell Biochem 2012;371:187-198.

21 Lu FH, Fu SB, Leng XN, Zhang XY, Dong SY, Zhao YJ, Ren H, Li HL, Zhong X, Zhang WH: Role of the CalciumSensing Receptor in Cardiomyocyte Apoptosis via the Sarcoplasmic Reticulum and Mitochondrial Death Pathway in Cardiac Hypertrophy and Heart Failure. Cell Physiol Biochem 2013;31:728-743.

22 Zhang XY, Zhang TM, Wu JC, Yang F, Yu XJ, Xu CQ Lu FH, Zhang WH: Calcium sensing receptor promoting cardiac fibroblats proliferation. Cell Physio Biochem 2014;33:414-423.

23 Taye A, Mekky M, Mohafe OM: Tempol ameliorates cardiac fibrosis in streptozotocin-induced diabetic rats: role of oxidative stress in diabetic cardiomyopathy. Naunyn-Schmiedeberg's Arch Pharmacol 2013;386:1071-1080. 


\section{Cellular Physiology Cell Physiol Biochem 2015;36:917-929 \begin{tabular}{c|c|}
\cline { 2 - 3 } DOI: 10.1159/000430266 & O 2015 S. Karger AG, Basel \\
\hline
\end{tabular}

24 Wang P, Li HW, Wang YP, Chen H, Zhang P: Effects of recombinant human relaxin upon proliferation of cardiac fibroblast and synthesis of collagen under high glucose condition. J Endocrinol Invest 2009;32:242-247.

25 Zhang M, Perino A, Ghigo A, Hirsch E, Shah AM: NADPH Oxidases in Heart Failure: Poachers or Gamekeepers? Antioxid Redox Signal 2013;18:1024-1032.

26 Bergman MR, Teerlink JR, Mahimkar R, Li L, Zhu BQ, Nguyen A, Dahi S, Karliner JS, Lovett DH: Cardiac matrix metalloproteinase-2 expression independently induces marked ventricular remodeling and systolic dysfunction. Am J Physiol Heart Circ Physiol 2007;292:H1847-H1860.

27 Fang ZY, Prins JB, Marwick TH: Diabetic cardiomyopathy: evidence, mechanisms, and therapeutic implications. Endocr Rev 2004;25:543-567.

28 Haidara MA, Yassin HZ, Rateb M, Ammar H, Zorkani MA: Role of oxidative stress in development of cardiovascular complications in diabetes mellitus. Curr Vasc Pharmacol 2006;4:215-227.

29 Anilkumar N, Sirker A, Shah AM: Redox sensitive signaling pathways in cardiac remodeling, hypertrophy and failure. Front Biosci 2009;14:3168-3187.

30 Ide T, Tsutsui H, Kinugawa S, Suematsu N, Hayashidani S, Ichikawa K, Utsumi H, Machida Y, Egashira K, Takeshita A: Direct evidence for increased hydroxyl radicals originating from superoxide in the failing myocardium. Circ Res 2000;86:152-157.

31 Martyn KD, Frederick LM, von Loehneysen K, Dinauer MC, Knaus UG: Functional analysis of Nox4 reveals unique characteristics compared to other NADPH oxidases. Cell Signal 2006;18:69-82.

32 Ushio-Fukai M: Localizing NADPH oxidase-derived ROS. Sci STKE 2006;re8.

33 Bedard K, Krause KH: The NOX family of ROS-generating NADPH oxidases: Physiology and pathophysiology. Physiol Rev 2007;87:245-313.

34 Heymes C, Bendail JK, Ratajiczak P, Cave AC, Samuel JL, Hasenfuss G, Shah AM: Increased myocardial NADPH oxidase activity in human heart failure. J Am Coll Cardiol 2003;41:2164-2171.

35 Cucoranu I, Clempus R, Dikalova A, Phelan PJ, Arivan S, Dikalov S, Sorescu D: NAD(P)H oxidase 4 mediates transforming growth factorbeta1- induced differentiation of cardiac fibroblasts into myofibroblasts. Circ Res 2005;97:900-907.

36 Byrne JA, Grieve DJ, Bendall JK, Li JM, Gove C, Lambeth JD, Cave AC, Shah AM: Contrasting roles of NADPH oxidase isoforms in pressure overload versus angiotensin II-induced cardiac hypertrophy. Circ Res 2003;93:802-805.

37 Kabil O, Banerjee R: Redox biochemistry of hydrogen sulfide. J Biol Chem 2010;285:21903-21907.

38 Yang G, Wu L, Jiang B, Yang W, Qi J, Cao K, Meng Q Mustafa AK, Mu W, Zhang S, Snyder SH, Wang R: H2S as a physiologic vasorelaxant: hypertension in mice with deletion of cystathionine gamma-lyase. Science 2008;322:587-590.

39 Papapetropoulos A, Pyriochou A, Altaany Z, Yang G, Marazioti A, Zhou Z, Jeschke MG, Branski LK, Hemdon DN, Wang R, Szabó C: Hydrogen sulfide is an endogenous stimulator of angiogenesis. Proc. Natl. Acad. Sci USA 2009;106:21972-21977.

40 Calvert JW, Elston M, Nicholson CK, Gundewar S, Jha S, Elrod JW, Ramachandran A, Lefer DJ: Genetic and pharmacologic hydrogen sulfide therapy attenuates ischemia-induced heart failure in mice. Circulation 2010;122:11-19.

41 Snijder PM, Frenay AS, de Boer RA, Pasch A, Hille Branks J, Leuvenink HG, Van Goor H: Exogenous administration of thiosulfate, a donor of hydrogen sulfide, attenuates Aniotensin-induced hypertensive heart disease in rats. Br J Paharmacol DOI: 10.1111/bph.12825.

42 Han Y, Zeng F, Tan G, Yang C, Tang H, Luo Y, Feng J, Xiong H, Guo Q: Hydrogen sulfide inhibits abnormal proliferation of lymphocytes via AKT/GSK3 $\beta$ signal pathway in systemic lupus erythematosus patients. Cell Physiol Biochem 2013;31:795-804. 